\title{
Article \\ Mixed Solvents in Multilayer Ceramic Capacitors (MLCC) Electronic Paste and Their Effects on the Properties of Organic Vehicle
}

\author{
Ruolong Gan ${ }^{1}$, Junrong Li $^{1}{ }^{1} * \mathbb{D}$, Xiuhua Cao ${ }^{2}$, Jun Huang ${ }^{2}$ and Liying Qian ${ }^{1, *(D)}$ \\ 1 School of Light Industry and Engineering, South China University of Technology, Guangzhou 510640, China; \\ 202021028911@mail.scut.edu.cn \\ 2 State Key Laboratory of Advanced Materials and Electronic Components, Zhaoqing 526020, China; \\ caoxh@china-fenghua.com (X.C.); squallhj1234@163.com (J.H.) \\ * Correspondence: 1ljrr@scut.edu.cn (J.L.); lyqian@scut.edu.cn (L.Q.); Tel.: +86-20-87111770 (J.L.)
}

Citation: Gan, R.; Li, J.; Cao, X.; Huang, J.; Qian, L. Mixed Solvents in Multilayer Ceramic Capacitors (MLCC) Electronic Paste and Their Effects on the Properties of Organic Vehicle. Polymers 2022, 14, 685. https://doi.org/10.3390/ polym 14040685

Academic Editor: Claudio Gerbaldi

Received: 6 December 2021

Accepted: 8 February 2022

Published: 11 February 2022

Publisher's Note: MDPI stays neutral with regard to jurisdictional claims in published maps and institutional affiliations.

Copyright: (C) 2022 by the authors. Licensee MDPI, Basel, Switzerland. This article is an open access article distributed under the terms and conditions of the Creative Commons Attribution (CC BY) license (https:// creativecommons.org/licenses/by/ $4.0 /)$.

\begin{abstract}
The copper end paste used in multilayer ceramic capacitors sintered in nitrogen atmosphere leads to carbon residues of organic vehicles, which leads to a reduction in electrode conductivity and high scrap rate. With an attempt to leave no residue in the sintering, the compatibility of solvents and thickeners should be improved because it has an important influence on the hierarchical volatilization and carbon residue of organic vehicles. In this work, the volatility of different solvents was compared, and several solvents were mixed in a definite proportion to prepare an organic vehicle with polyacrylate resins. The hierarchical volatility and solubility parameters of mixed solvents were effectively adjusted by changing proportions of different components. The thermogravimetric curves of resins and organic vehicles were measured by thermogravimetric analyzer, and the effect of solubility parameter on the dissolvability of resins in the solvent and the residual of organic vehicles were studied. Results showed that the hierarchical volatilization of solvents can be obtained by mixing different solvents; the intrinsic viscosity of the organic vehicle is higher, and the thermal decomposition residue of polyacrylate resins is lower when the solubility parameters of mixed solvents and polyacrylate resins are closer. The low residual sintering of organic vehicles can be achieved by using a mixed solvent with hierarchical volatility and approximate solubility parameters as resins.
\end{abstract}

Keywords: electronic paste; organic vehicle; mixed solvents; solubility parameter; low residual rate

\section{Introduction}

As one of the three basic components, the multilayer ceramic capacitor (MLCC) has the advantages of small size, high frequency, and low cost compared with other components; therefore, MLCC is widely used in various electronic products and is gradually replacing traditional aluminum electrolytic capacitors, which is one of the most widely used capacitors. MLCC is widely used in electronic equipment such as radio and television, mobile communication, and measuring instruments. With the continuous upgrading of electronic products such as smartphones, and the popularization of new communication technologies, MLCC has a huge demand in the market. With the increasing demand for MLCC in the market, the requirements of electronic information products for MLCC tend to be high frequency, low power consumption, miniaturization, superior energy storage, and low cost [1]. Copper end electronic paste is composed of three main components: conductive phase (copper), bonding phase (glass or oxide crystals), and organic vehicle. The organic vehicle consists of an organic solvent and thickener, in which the organic solvent accounts for $65-98 \%$. In addition, polyacrylate resin is commonly used as the thickener in the organic carrier, and the sintering residue of the organic vehicle mainly depends on the thermal 
degradation of the polyacrylate resin thickener in the solvent. Cu electrodes with better conductivity have replaced precious-metal electrodes as the mainstream electrode material [2]; however, due to the oxidation characteristics of $\mathrm{Cu}$, sintering can only be performed in nitrogen. Carbon residue caused by sintering $\mathrm{Cu}$ end slurry in a nitrogen atmosphere poses a great challenge to the selection of the organic vehicle composition of base metal inner electrode multilayer ceramic capacitors (BME-MLCC) [3]. The residual rate of thickener in organic vehicles is the key factor to determine the conductivity of electrodes [4]. The remaining carbon in the conductive film greatly affects the electroconductibility of the film. There are copious studies on the effects of sintering atmosphere, temperature, rate, and time on electroconductibility [5-10], but the effect of thermal degradation characteristics of a thickener on carbon residue is still not clear, and the thickener is the main component of the organic vehicle that applied in MLCC. Therefore, it is of practical significance to develop methods to select a mixed solvent with hierarchical volatility and to prepare organic vehicles with extremely low residue on the basis of the relationship between the mutual solubility of mixed solvents and thickeners.

An organic vehicle is generally composed of solvent, thickener, surfactant, thixotropic agent, and other additives. The organic solvent is the primary component of the organic vehicle, with about $65-98 \%$ of the total mass of the organic vehicle. It should dissolve the thickener quickly with excellent solubility and have a high boiling point to avoid volatilization in preparing the organic vehicle. The organic vehicle with mixed solvent can adjust the volatilization characteristics of solvents, and achieve hierarchical volatilization leading to nonvolatilization at low temperatures, and continuous and rapid volatilization at drying temperatures [11]. Meanwhile, it can improve the viscosity and fluidity of slurry, and enhance its stability and printability. In addition, the reasonable selection of mixed solvents can enhance thickener solubility and the wettability of copper, which greatly improves the performance of electronic paste in MLCC.

In this paper, according to the volatilization characterizes of different solvents, mixed solvents with different components were prepared, and the key factors of the hierarchical volatilization of organic vehicles were explored. In order to investigate the wettability of copper powder and glass powder in mixed solvents, contact-angle data were measured by a contact-angle tester. According to the solubility parameter close principle, solubility parameters of mixed solvents and polyacrylate resins were calculated and compared, while the intrinsic viscosity of polyacrylate resins in the mixed solvents was measured, and the relationship between solubility parameters and intrinsic viscosity of the organic vehicles was clarified. Furthermore, the thermal properties and residual rate of organic vehicles were characterized by TG, and the effect of compatibility between the mixed solvent and polyacrylate resins on the residue of organic vehicle was analyzed.

\section{Experiments}

\subsection{Materials}

Terpineol (T) and N, N-dimethylformamide (DMF) were purchased from Tianjin Damao Chemical Reagent Factory, China. Diethylene glycol butyl ether (DGBE), diethylene glycol butyl ether acetate (DBAC), and ethylene glycol ethyl ether acetate (CAC) were purchased from Macklin, China. All reagents were analytical-grade without further treatment before use. Copper powder and glass powder were provided by Guangdong Fenghua High Tech Co., Ltd., Fenghua, China. Polyacrylate resins A (DEGALAN ${ }^{\circledR}$ LP65 $/ 11$, $\mathrm{Mw} \approx 30,000 \mathrm{~g} / \mathrm{mol}$ ) and polyacrylate resins B (DEGALAN ${ }^{\circledR} \mathrm{LP} 65 / 12, \mathrm{Mw} \approx 44,000 \mathrm{~g} / \mathrm{mol}$ ) were purchased from Degussa, Germany. Monomers of polyacrylate resin were methyl methacrylate (MMA) and butyl methacrylate (BMA).

\subsection{Characterization}

\subsubsection{Constant Temperature Volatility of Solvent}

The constant temperature volatilization test of the solvent was carried out on a collector-type magnetic heating agitator (DF-101S, Shandong Kecheng Scientific Instrument 
Co., Ltd., Heze, Shandong, China). We weighed $20 \mathrm{~g}$ each of five pure solvents or mixed solvents into a $50 \mathrm{~mL}$ beaker and they were marked as $m_{1}$. When the oil bath reached 70 , $90,110,130,150,170$, and $190^{\circ} \mathrm{C}$, the beaker was placed inside it, and the temperature was maintained constant for $15 \mathrm{~min}$. Then, the breaker was taken out and cooled to indoor temperature, weighed, and marked as $m_{2}$. Volatilization was calculated according to Formula (1), and results were calculated by averaging the three repeated experiments. $T$ was used as the main solvent to prepare the mixed solvent with the four other solvents at a mass ratio of 50:50, marked as T-XX, where T represents terpineol, and XX is the abbreviation of another solvent. For example, T-DMF represents the mixed solvent prepared with terpineol and DMF at a mass ratio of 50:50.

$$
\text { Volatilization }=\frac{m_{1}-m_{2}}{m_{0}} \times 100 \%,
$$

where $m_{0}$ is the actual weight of the solvent.

\subsubsection{Wettability of Copper Powder and Glass Powder to Mixed Solvents}

After the copper powder or glass powder had been pressed into a sheet by a desktop electric tablet press (FYD-20, SCJS, Tianjin, China), the static contact angle of the copper or glass powder sheet to the mixed solvent was tested by contact-angle tester (Attentions Theta Flex, Biolin Scientific, Gothenburg, Sweden). The measurement was repeated twice to ensure reproducibility.

\subsubsection{Intrinsic Viscosity of Polyacrylate Resins in the Mixed Solvents}

The diluted Ubbelohde viscometer (1834B, Zonwon, Hangzhou, China) was placed vertically in a high-precision thermostatic bath (VT2, ZONWON, Hangzhou, China) at $30 \pm 0.01{ }^{\circ} \mathrm{C}$, outflow time of the solvent was marked as $\mathrm{t}_{0}$, and $\mathrm{t}_{1}$ of the solution of $1.00 \%$ polyacrylate resins $\mathrm{A}$ or $\mathrm{B}(10 \mathrm{~mL}) ; 5 \mathrm{~mL}$ of solvent was added into the viscometer for dilution each time, the concentration of the solution decreased to $0.67 \%, 0.50 \%, 0.40 \%$, or $0.33 \%$, and the outflow time of the diluted solution were recorded as $t_{2}, t_{3}, t_{4}$, and $t_{5}$, respectively. The measurement was repeated three times to obtain the average. The intrinsic viscosity $(\eta)$ was obtained by extrapolation.

\subsubsection{Thermogravimetric Analysis (TGA)}

TGA was carried out on a thermogravimetry analyzer (TG209F1, Netzsch, Germany). Terpineol, DMF, and polyacrylate resins A were weighed according to the mass ratio (at 35:35:30) to prepare the organic vehicle recorded as PA-T-DMF, where PA represents polyacrylate resins $\mathrm{A}$, and $\mathrm{T}$ represents terpineol. In the same way, the sample number of organic vehicles composed of mixed solvents and polyacrylate resins B was marked as PB-T-XX. Then, $10 \mathrm{mg}$ of the organic vehicles was produced by thermogravimetry in a nitrogen atmosphere with a temperature range of $40-600^{\circ} \mathrm{C}$, heating rate of $20^{\circ} \mathrm{C} / \mathrm{min}$. The mass change $(\Delta m \%)$ was then recorded in the decomposition stage of polyacrylate resins in the thermal decomposition curve.

\section{Results and Discussion}

\subsection{Constant Temperature Volatility of Solvent}

The volatilization characteristics of organic vehicles are closely related to the manufacturing process of thick-film electronic components, which play an important role in the printability, drying, and sintering process of electronic pastes [11]. The organic vehicle should not be volatile at room temperature, which is conducive to the storage stability of the slurry. In the drying temperature period, the slurry should volatilize rapidly, which can shorten the processing time. Therefore, the organic vehicle should have a hierarchical volatilization curve [12]. The organic solvent is an important part of preparing organic vehicles, which is to dissolve thickeners and adjust the slurry. In the sintering process, if the organic vehicle volatilizes too slowly, it results in sagging at the edge of the end 
electrode because of the decrease in slurry viscosity at high temperature; if the organic vehicle volatilizes too fast, it leads to holes in the film because of a large amount of escaped gas. The electrical properties of MLCC are closely linked to film quality. Therefore, a variety of solvents with different boiling points are often used to form a mixed solvent with a hierarchical volatilization curve. The thickener should have commendable solubility in mixed solvents, which has the characteristics of nonvolatility at low temperatures and rapid hierarchical volatilization during drying.

The volatilization properties of pure and mixed solvents with a mass ratio of 50:50 are shown in Figure 1. The volatilization amount of all solvents increases continuously with the increase in temperature in the overall trend. The evaporation rates of pure solvents from high to low are DMF, CAC, T, DGBE, and DBAC, which corresponded to their boiling points at $152.8,156,217,227$, and $246.4^{\circ} \mathrm{C}$, respectively. This is in line with the law of easy volatilization with a low boiling point. The volatilization amounts of $\mathrm{DMF}$ and $\mathrm{CAC}$ with low boiling points were more than half at $150{ }^{\circ} \mathrm{C}$, and they were almost completely volatilized at $190^{\circ} \mathrm{C}$. The volatilizations of DGBE and DBAC with high boiling points were indubitably small at $150{ }^{\circ} \mathrm{C}$; although volatilizations were increased to 3 times at $190{ }^{\circ} \mathrm{C}$, volatilizations below $40 \%$ were too small to meet the satisfactory sintering process of organic vehicles. In contrast, $\mathrm{T}$ volatilizes slowly at low temperatures and rapidly at $150-190{ }^{\circ} \mathrm{C}$; volatilization at $190{ }^{\circ} \mathrm{C}$ was nearly twice that at $150{ }^{\circ} \mathrm{C}$, which shows the excellent characteristics of not easy volatilization at low temperatures and rapid volatilization at high temperatures. Therefore, the use of $\mathrm{T}$ as a main component in the mixed solvents can effectively avoid problems such as film cavities and sagging after sintering. The volatilizations of T-DMF and T-CAC were lower than those of DMF and CAC because of the relatively lower volatilization ability of $\mathrm{T}$ in the mixed solvents. $\mathrm{T}$, on the other hand, had better volatilization ability than that of DGBE and DBAC, which led to a higher volatilization amount of T-DGBE and T-DBAC.

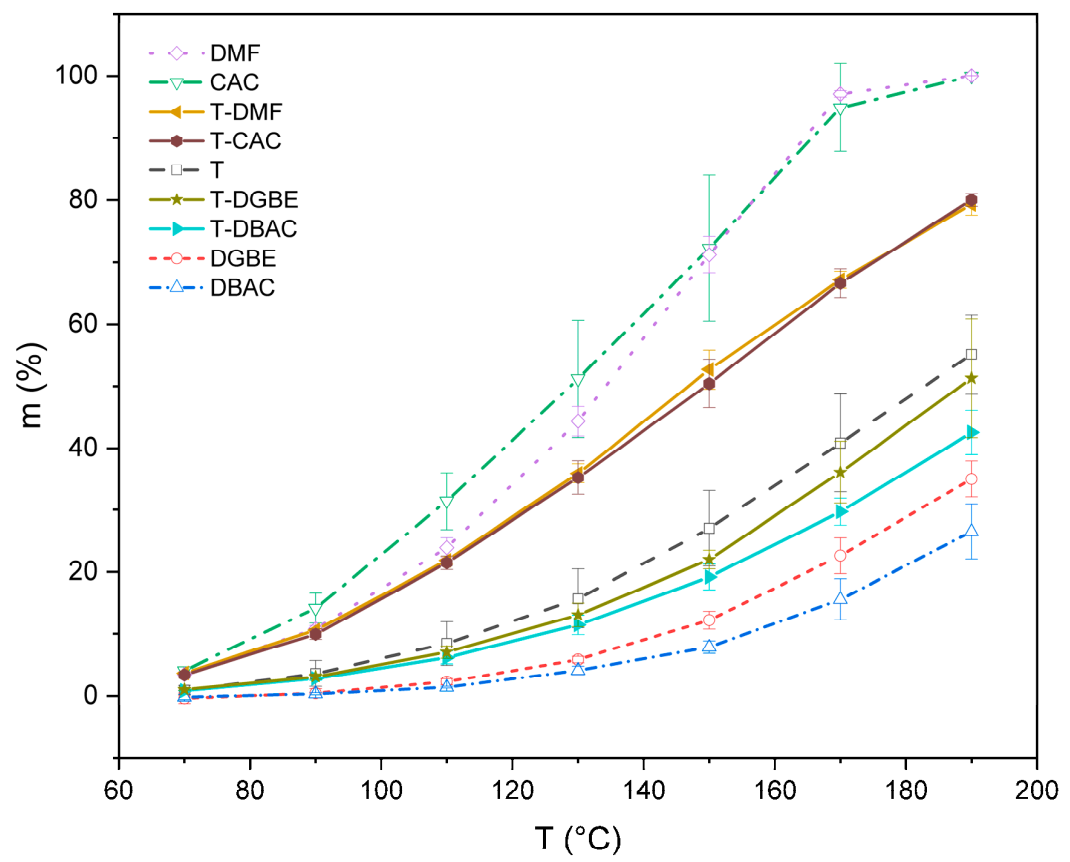

Figure 1. Volatilization curve of pure and mixed solvents; mean values plotted with error bars representing standard deviation.

An effective method to adjust volatilization is by combining solvents with different boiling points. This can be attributed to the partial pressure of the mixed solvent. According to Henry's law [13], under a certain temperature and equilibrium state, the relative content of the mixed solvent determines the relative ratio of vapor pressure. The ratios of the four mixed solvents are consistent before thermal volatilization. In the process of the thermal 
volatilization of T-DMF and T-CAC, the two solvents with low boiling points (DMF and CAC) preferentially volatilized at low temperatures. However, $\mathrm{T}$ had less volatilization at low temperatures. Different volatilization rates result in an increased relative ratio of $\mathrm{T}$ to DMF and CAC after volatilization for a period, the partial pressure of $\mathrm{T}$ increased, and the partial pressure of DMF and CAC decreased, which caused more volatilization of $\mathrm{T}$. For T-DGBE and T-DBAC, T was the component with a low boiling point and it mainly volatilized at the beginning. With the change in partial pressure, the volatilization of DGBE and DBAC increased. Therefore, mixed solvents with proper proportions can achieve hierarchical volatilization to avoid uneven volatilization. However, the adjustment ability of mixed solvents with only two components is not sufficient to meet the requirements. It is necessary to investigate the volatilization of mixed solvents with more components, and provide the flexible solvent formulation with good hierarchical volatilization.

On the basis of the volatilization results of solvents, CAC showed the most rapid volatilization and the largest standard deviation due to its low boiling point. To reduce the error of solvent volatilization, a small amount of CAC was utilized to prepare a mixed solvent for adjusting volatilization in relatively low temperatures. At the same time, $\mathrm{T}$ and DBAC had better volatilization stability, which made them suitable as the primary components of mixed solvents to investigate the effects of different ratios on the volatilization characteristics of mixed solvents. The volatilization characteristics of mixed solvents composed of T, DBAC, and CAC in different proportions were studied; mass fraction, volatilization curves, and amounts are shown in Figure 2 and Table 1. From the volatilization curves, the mixed solvents added with CAC showed better hierarchical volatilization, and Sample 4 showed the most obvious hierarchical volatilization characteristics. In the range of $40-130^{\circ} \mathrm{C}$, the rising range of volatilization curve was small, showing the first level of the curve. In the range of $130-170{ }^{\circ} \mathrm{C}$, the solvent began to volatilize rapidly, and the rising range of the volatilization curve increased, showing the second level of the curve compared with the previous stage. After $170{ }^{\circ} \mathrm{C}$, the rise of the volatilization curve was more obvious than that of the previous stage, showing the third level of the curve. In summary, the mixed solvent showed multilevel volatilization with slow volatilization at low temperatures, and rapid volatilization at high temperatures.

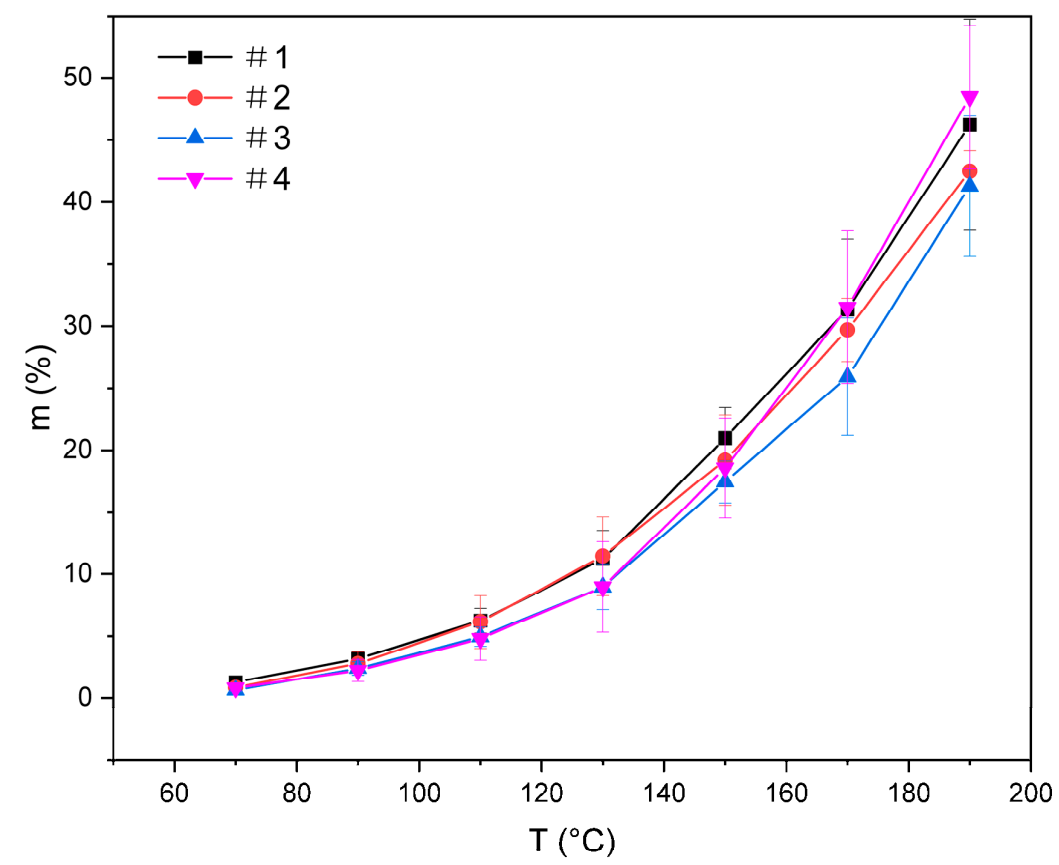

Figure 2. Volatilization curve of mixed solvents with various mass ratios; mean values plotted with error bars representing standard deviation. 
Table 1. Composition of mixed solvents and their volatilization amount at different temperatures.

\begin{tabular}{|c|c|c|c|c|c|}
\hline \multirow{2}{*}{ Sample } & \multirow{2}{*}{$\begin{array}{c}\mathrm{T} \\
(w \mathrm{t} / \%)\end{array}$} & \multirow{2}{*}{$\begin{array}{l}\text { DBAC } \\
(w t / \%)\end{array}$} & \multirow{2}{*}{$\begin{array}{c}\text { CAC } \\
(w t / \%)\end{array}$} & \multicolumn{2}{|c|}{ Vol (\%) } \\
\hline & & & & $150^{\circ} \mathrm{C}$ & $190^{\circ} \mathrm{C}$ \\
\hline 1 & 50 & 40 & 10 & 20.96 & 46.24 \\
\hline 2 & 50 & 50 & 0 & 19.20 & 42.51 \\
\hline 3 & 30 & 60 & 10 & 17.44 & 41.28 \\
\hline 4 & 60 & 30 & 10 & 18.56 & 48.48 \\
\hline
\end{tabular}

From Table 1, the volatilization amount of the four mixed solvents at $190{ }^{\circ} \mathrm{C}$ is more than twice that at $150{ }^{\circ} \mathrm{C}$, and the volatilization amount of Sample 4 at $190{ }^{\circ} \mathrm{C}$ was the highest, showing commendable volatilization performance.

This was mainly due to the difference in boiling points of the three components. According to Figure 1, the volatilization of the three solvents was small at a low temperature, and the DBAC with a high boiling point was basically nonvolatile. The partial pressure of the mixed solvent was mainly concentrated in the relative content of T and DBAC, and the volatilization curve rose gently. With the temperature being close to the boiling point of CAC, CAC began to volatilize a large amount, and the volatilization curves increased rapidly. As the temperature rose to $170{ }^{\circ} \mathrm{C}, \mathrm{CAC}$ was completely volatilized due to its small relative content, and the volatilization of the solvent was mainly concentrated in the covolatilization of $\mathrm{T}$ and $\mathrm{DBAC}$. Compared with $\mathrm{CAC}, \mathrm{T}$ and $\mathrm{DBAC}$ had greater relative content, so the volatilization curve showed a greater increase range. Furthermore, the relative content of $\mathrm{T}$ in Sample 4 was greater than that of $\mathrm{DBAC}$, and the volatilization capacity of T was better than that of DBAC, so the rising range of the volatilization curve was greater, and the hierarchy was the most obvious. The volatilization ability of Sample 3 was the worst because of the highest content of DBAC in the mixed solvent. The hierarchical volatilization of the mixed solvents could thus be effectively adjusted by adjusting the proportion of the solvent components $[11,14,15]$. Therefore, the slurry prepared with the organic vehicle with hierarchical volatilization could achieve satisfactory discharge and sintering [16].

\subsection{Wettability of Mixed Solvents to Glass Powder and Glass Powder}

As a base metal with excellent conductivity, $\mathrm{Cu}$ has in recent years gradually attracted much attention in the field of electronic paste. Da Costa et al. stated that the dispersion of copper plays the most important role in sintering, and it is the main agent responsible for densification in both solid and liquid states [17]. The wettability of mixed solvent to the copper powder sheet is shown in Figure 3, which indicates that the four mixed solvents had satisfactory wettability to the copper powder sheet. Contact angles were all below $10^{\circ}$, which was close to complete wetting. Moreover, the wettability of the four mixed solvents to the glass powder was complete wetting (Figure S1, Videos S1-S4, see the supporting material for detailed data). According to the contact-angle data of the solvent on the metal particles and glass powder, the four mixed solvents with a mass ratio of 50:50 met the requirements of commendable wettability to the bonding and conductive phases. The better wettability of mixed solvents to copper and glass powders is beneficial to the dispersibility of particles in the slurry and the uniformity of sintering products. When the slurry is sintered, the glass powder softens, and the liquid organic vehicle can freely come into contact with the adjacent copper conductive phase. With the increase in temperature, metal particles rearrange and tend to be close. During the cooling process, the glass powder shrinks, the metal particles are in close contact, and a satisfactory conductive path is formed $[18,19]$. 


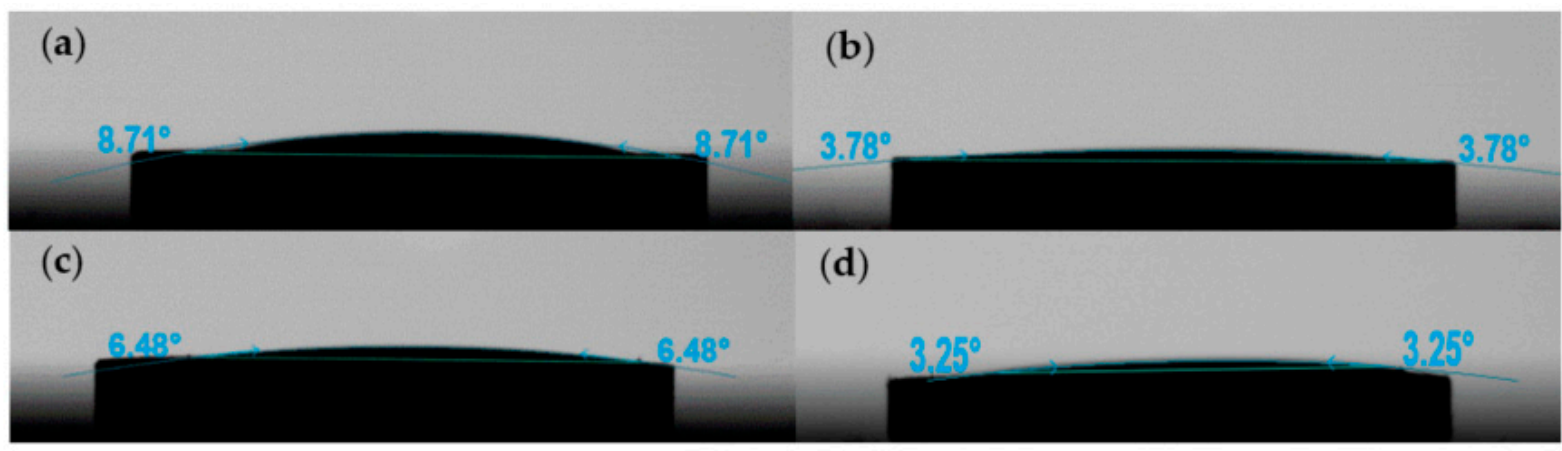

Figure 3. Contact angles of mixed solvents on copper powder sheet. (a) T-DMF; (b) T-DBAC; (c) T-DGBE; (d) T-CAC.

\subsection{Solubility of Polyacrylate Resins in Mixed Solvents}

Polyacrylate resin is often used as a thickener in electronic paste, the solubility of solvent to thickener is genuinely important for film-forming quality. It not only has an important impact on the rheology of organic vehicles, but also plays a certain role in the thermal degradation of polyacrylate resin; better solubility can effectively reduce the thermal degradation residue of thickeners. When the solubility parameters of solvent and thickener are closer, it is generally considered that the thickener has stronger solubility in solvents. According to Hansen's dissolution parameter theory, the group contribution method is often used to calculate solubility parameters $\delta$ of polymers [20,21]. Hansen et al. proposed to divide the cohesive energy into three parts, i.e., $E=F_{d}+F_{p}+F_{h}$, where $F_{d}, F_{p}$, and $F_{h}$ are the contribution values of dispersion forces, dipole force, and hydrogen bonding, respectively. Therefore, solubility parameters can be calculated as follows:

$$
\delta^{2}=\delta_{d}^{2}+\delta_{p}^{2}+\delta_{h}^{2}
$$

$\delta_{d}$ is the dispersion solubility parameter, $\delta_{p}$ is the polar solubility parameter, and $\delta_{h}$ is the hydrogen bond solubility parameter.

The three-dimensional solubility parameters of copolymers such as polyacrylate resins can be calculated by the mole fraction weighted average of homopolymer solubility parameters [22]:

$$
\delta=\sum \delta_{i} \phi_{i}
$$

where $\phi_{i}$ is the mole fraction of component $i$.

Due to the limitations of the classical model for calculating the solubility parameters of mixed solvents, Yang Long et al. [23] proposed a new nonlinear mathematical model calculation method to accurately calculate the solubility parameters of mixed solvents, and introduced the volume components of solvents as calculation parameters. The solubility parameters of mixed solvents are calculated as follows:

$$
\delta_{t, m}^{2}=\psi_{1} \delta_{t, 1}^{2}+\psi_{2} \delta_{t, 2}^{2}+\ldots+\psi_{n} \delta_{t, n}^{2}
$$

$\psi_{i}$ represents the volume component of component $j$, and $\delta^{2} t, m$ represents the square of solubility parameters in each dimension.

According to the three-dimensional solubility parameters of solvents and monomers of resins in Table S1, the solubility parameters of polyacrylate resins and mixed solvents are calculated according to Formulas (3) and (4), as shown in Table 2. The solubility parameters and intrinsic viscosity of the organic vehicles with polyacrylate resin A are shown in Figure 4. 
Table 2. Three-dimensional solubility parameters of solvents and resins.

\begin{tabular}{ccccc}
\hline Sample & $\delta_{\boldsymbol{d}}\left(\mathbf{J}^{1 / 2} \cdot \mathbf{c m}^{-3 / 2}\right)$ & $\delta_{\boldsymbol{p}}\left(\mathbf{J}^{1 / 2} \cdot \mathbf{c m}^{-3 / 2}\right)$ & $\delta_{\boldsymbol{h}}\left(\mathbf{J}^{1 / 2} \cdot \mathbf{c m}^{-3 / 2}\right)$ & $\delta\left(\mathbf{J}^{1 / 2} \cdot \mathbf{c m}^{-3 / 2}\right)$ \\
\hline A and B & 16.59 & 4.20 & 7.71 & 18.77 \\
T-DMF & 17.25 & 10.41 & 11.30 & 23.10 \\
T-DBAC & 16.56 & 4.87 & 9.93 & 19.91 \\
T-CAC & 16.56 & 5.13 & 11.01 & 20.54 \\
T-DGBE & 16.56 & 6.26 & 11.01 & 20.85 \\
\hline
\end{tabular}

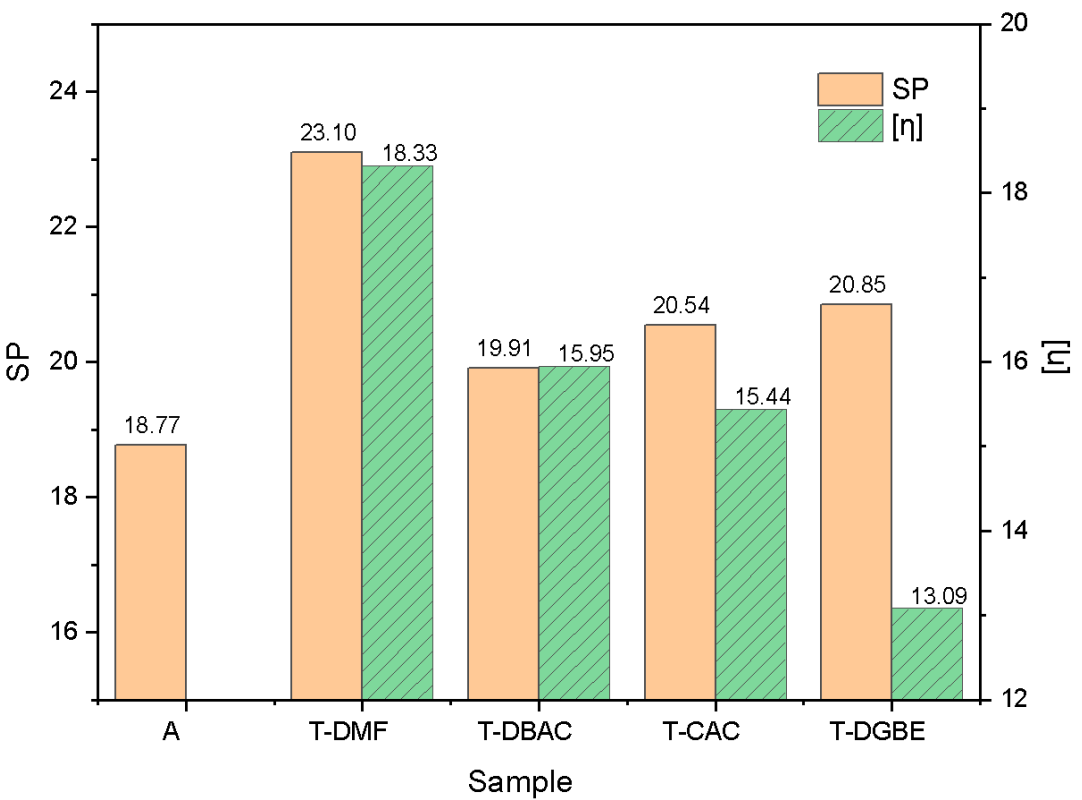

Figure 4. Solubility parameters (SP) and intrinsic viscosity of organic vehicles with polyacrylate resin $\mathrm{A}$.

The solubility parameters of polyacrylate resins A and B were 18.77 because their monomer compositions were the same. The solubility parameters of the four mixed solvents T-DMF, T-DBAC, T-CAC, and T-DGBE were 23.10, 19.91, 20.54, and 20.85, respectively. Among them, the solubility parameter of T-DBAC was the closest to that of resins, and the difference between the solubility parameters of T-DMF and resins was the largest, especially for the polar solubility parameter $\left(\delta_{p}\right)$. When the solubility parameters of polymers are equal to the solubility parameters of solvents, the intrinsic viscosity of their solutions is maximized [24] because of the commendable thermodynamic properties. However, as shown in Figure 4, the organic vehicle of T-DMF, which had the largest difference in solubility parameters from polyacrylate resin $\mathrm{A}$, showed the highest intrinsic viscosity, while the organic vehicles of T-DBAC, T-CAC, and T-DGBE conformed to the rules that the smaller the difference in solubility parameters from polyacrylate resin $\mathrm{A}$ is, the greater the intrinsic viscosity of organic vehicle.

DMF is a strongly polar organic solvent with a high polar solubility parameter component. Therefore, the chain stretching process of polyacrylate resin A in T-DMF is mainly controlled by the component of the polar solubility parameter. High polarity completely stretches the molecular chain, so it has larger hydrodynamic volume and greater intrinsic viscosity. Eom and Kim studied the dissolution process of polyacrylonitrile (PAN) in DMF and DMSO [25], and found that the solubility parameter of DMF $(\delta=24.8)$ was closer to PAN $(\delta=25.3)$ than to DMSO $(\delta=26.6)$. However, experimental results showed that the hydrodynamic diameter of PAN and intrinsic viscosity of solution in DMSO were higher than those in DMF. This may have mainly been caused by the higher polar solubility parameter component of DMSO than that of DMF. Similarly, it also explains the behavior of the intrinsic viscosity of the organic vehicle with A dissolved in T-DMF in this paper. 
For the three other mixed solvents with similar three-dimensional solubility parameters as those of polyacrylate resin $\mathrm{A}$, the hydrodynamic volume of the polymer in the solvent was determined by the solvent. In the solvent that had high affinity (good solvent) for the polymer, it was easy to be dissolved, and the molecular chain was stretched, which resulted in it having large hydrodynamic volume. On the other hand, if the polymer was dissolved in a solvent with low affinity (inferior solvent), the polymer molecular chain was curled up and thus had relatively small hydrodynamic volume [26,27]. Intrinsic viscosity refers to the contribution of a single molecule to the solution viscosity. Since the hydrodynamic volume of the polymer is directly proportional to the viscosity of the polymer solution, the intrinsic viscosity of the polymer solution dissolved in a good solvent is greater than that of inferior solvents [26-28].

\subsection{Analysis of Thermogravimetric Results}

\subsubsection{Thermogravimetric Analysis of Polyacrylate Resins}

To prevent the poor conductivity caused by oxidation when the copper end is sintered in oxygen atmosphere, the copper electrode MLCC is mostly sintered in a nitrogen atmosphere. In the copper-end slurry in MLCC, the incomplete thermal decomposition of a thickener in a nitrogen atmosphere causes carbon residue on the surface of the copper powder. Therefore, the selected thickener should have low residue levels in a nitrogen atmosphere. The thermogravimetric analysis results of A and B are shown in Figure 5.

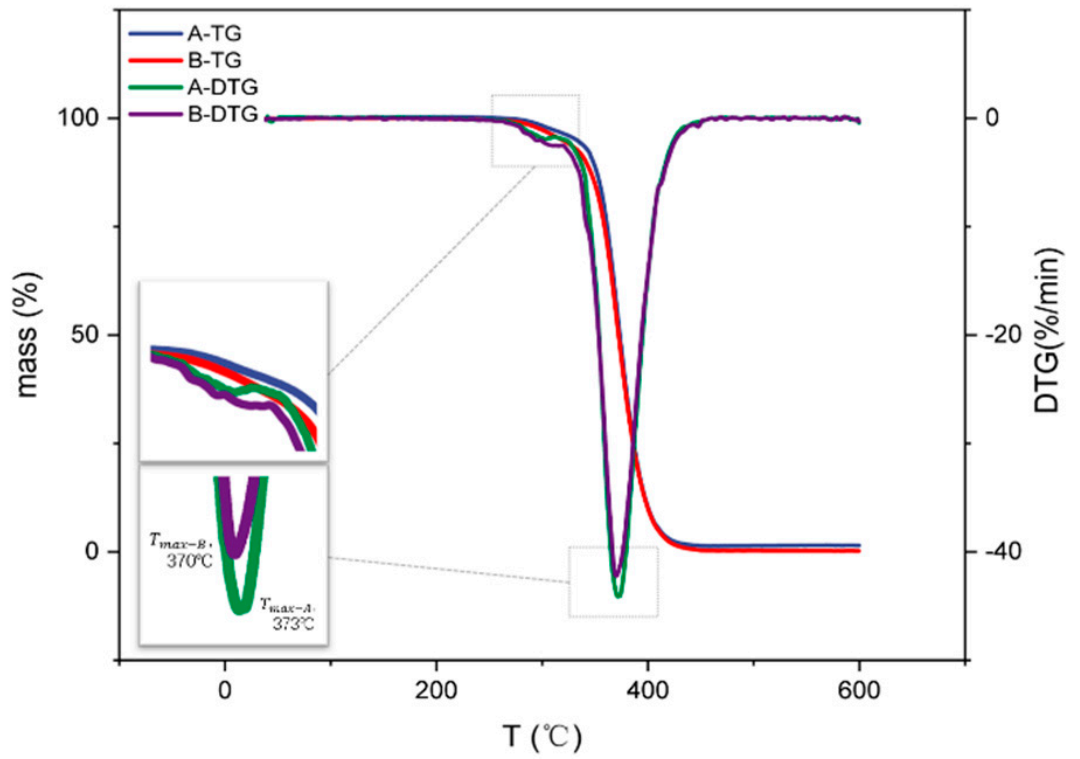

Figure 5. Thermogravimetric curves of polyacrylate resins A and B.

The initial decomposition temperature of the sample was about $260{ }^{\circ} \mathrm{C}$, and it was completely decomposed at about $460{ }^{\circ} \mathrm{C}$, with the final residue rates as $1.46 \%$ and $0.21 \%$, respectively. Comparing resin $\mathrm{A}$ and resin $\mathrm{B}$, resin $\mathrm{B}$ showed a lower initial decomposition temperature and lower maximal decomposition rate temperature: $\mathrm{T}_{\max }$, was about $3{ }^{\circ} \mathrm{C}$ lower than that of $\mathrm{A}$. With the same monomer compositions, the thermal decomposition stability of polymers is mainly influenced by molecular weight. The higher the molecular weight is, the worse the thermal stability, because the activation energy of polymer degradation decreases with the increase in molecular weight [29]. Meanwhile, the enhanced extraction of intermolecular hydrogen at high temperatures results in chain scission and increased thermal decomposition [30]. The longer chains showed a great tendency to form tight curves. The resulting bond angular strain led to a higher $\mathrm{C}-\mathrm{C}$ scission rate [31]. In general, an increase in molecular weight increases the contribution of random fractures, resulting in different end-group structures. 
The thermogravimetric curve showed two thermal decomposition peaks that were more visible in DTG curve, of which the thermal decomposition peak of near $370{ }^{\circ} \mathrm{C}$ was the most obvious. The thermal decomposition process of $\mathrm{A}$ and $\mathrm{B}$ in nitrogen atmosphere can be divided into two stages: the first stage was at $260-320^{\circ} \mathrm{C}$; the weight loss in this stage was not obvious, and it mainly involved the volatile decomposition of residual solvents and small molecular components in the polymer [32]. The second stage was at $320-460{ }^{\circ} \mathrm{C}$; the weight loss was the most notable, and the weight loss rate reached $95 \%$. The second degradation stage represents the degradation of A and B into small monomer molecules $[33,34]$. The resin produced an alkyl methacrylate monomer and a small number of other decomposition products, such as carbon monoxide, carbon dioxide, ethane, methanol, ethanol, and 1-propanol [35,36]. With the continuous fracture of the end-group structure, and the decomposition products volatilizing, the weight loss gradually increased.

\subsubsection{Thermogravimetric Analysis of Organic Vehicles}

The organic vehicle is the key to the electronic slurry in MLCC, which plays a role in dispersing all phases and adjusting the performance of the slurry. In the process of debinding the electronic paste $\left(150-250{ }^{\circ} \mathrm{C}\right)$, the organic solvent in the paste needs to have commendable volatile properties; in the sintering process of electronic paste $\left(250-600^{\circ} \mathrm{C}\right)$, the polyacrylate resin is required to reach better thermal degradation performance and no residue. The organic vehicle should have commendable thermal degradation performance and low residue to ensure the normal discharge process of the slurry. The TGA of organic vehicles prepared by different mixed solvents and resins was tested, and results are shown in Figure 6.

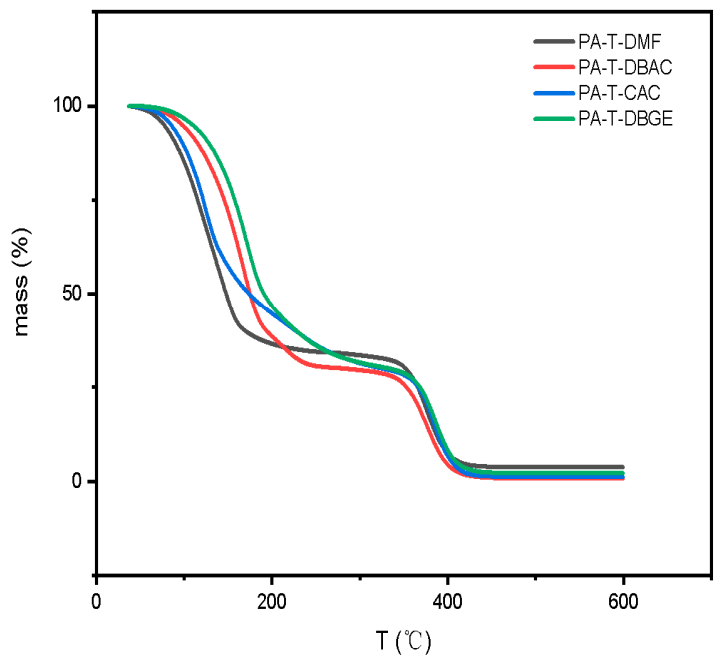

(a)

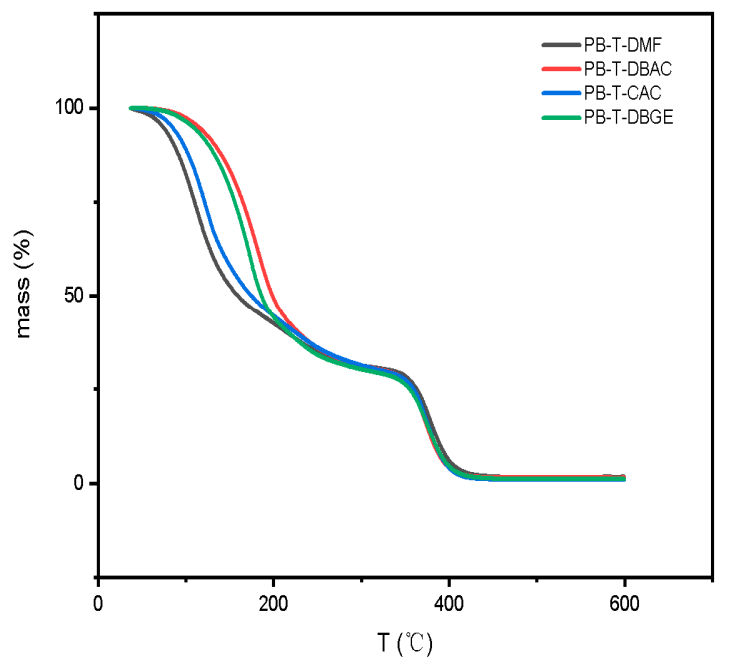

(b)

Figure 6. Thermogravimetric curve of organic vehicles with (a) resin A and (b) resin B.

The thermal decomposition curve of the organic vehicle can be divided into two stages: the first stage was at $40-320^{\circ} \mathrm{C}$, and the weight loss rate was close to $70 \%$. The weight loss at this stage was mainly caused by the thermal volatilization of the mixed solvents in the organic vehicles. Among them, the weight loss is also associated with the volatilization of the solvents. For both organic vehicles, the weight loss with mixed solvents of T-DMF and T-CAC started at lower temperatures because of the low boiling points of DMF and $\mathrm{CAC}$. In the second stage of $320-460{ }^{\circ} \mathrm{C}$, mixed solvents were completely volatilized, and the polyacrylate resins underwent thermal decomposition. Therefore, the weight loss rate was about $30 \%$, which was the proportion of resins in the organic vehicles.

Comparing the thermogravimetric curves of different organic vehicles, the thermal decomposition of resin in PA-T-CAC and PA-T-DGBE began at $320^{\circ} \mathrm{C}$, the polyacrylate 
resins in PA-T-DMF and PA-T-DBAC had a lower thermal decomposition starting temperature, which was $10-20^{\circ} \mathrm{C}$ lower than that in PA-T-CAC and PA-T-DGBE. This result indicates that T-DMF and T-DBAC reduced the thermal stability of resins $\mathrm{A}$ and $\mathrm{B}$ because the curled-chain structure of the polymer was stretched, and the hydrodynamic volume and free volume increased more in a good solvent $[26,27]$, resulting in a reduction in the distance between molecular chains, and the decreased energy destroying the chemical bond in the molecular chain; therefore, the thermal decomposition temperature decreased to a certain extent. This shows that the intrinsic viscosity of the organic vehicle qualified as a reasonable indicator for the thermal decomposition of resin, as the intrinsic viscosity of resin A in T-DMF and T-DBAC was greater than that in T-CAC and T-DGBE. However, the solvent had no effect on the thermal stability of $B$. On the one hand, the solvent had a more obvious effect on the low-molecular-weight resin; on the other hand, the thermal decomposition of high-molecular-weight polymers is faster than that of a low-molecular-weight polymer.

To further verify the relationship between the intrinsic viscosity $(\eta)$ and residual mass of resins $\mathrm{A}$ and $\mathrm{B}$, intrinsic viscosity and mass changes $\Delta m \%$ of the organic vehicle in the range of $320-460{ }^{\circ} \mathrm{C}$ are summarized in Figure 7 . The intrinsic viscosity was directly proportional to the thermal decomposition degree of resins $\mathrm{A}$ and $\mathrm{B}$. With the highest intrinsic viscosity, PA-T-DMF and PB-T-DMF showed the greatest degree of thermal decomposition, the mass change rate $\Delta m \%$ was $29.58 \%$ and $29.10 \%$ (the mass ratio of $\mathrm{A}$ and $\mathrm{B}$ in the organic vehicle was 30\%), and the thermal decomposition rate was $98.6 \%$ and $97.0 \%$, respectively. PA-T-DGBE and PB-T-DGBE had the lowest intrinsic viscosity, which shows the lowest degree of thermal decomposition with the mass change $\Delta m \%$ as $28.46 \%$, and the thermal decomposition rate as $94.87 \%$. Thus, the greater the intrinsic viscosity of organic vehicles is, the more completed the thermal decomposition with less residue.

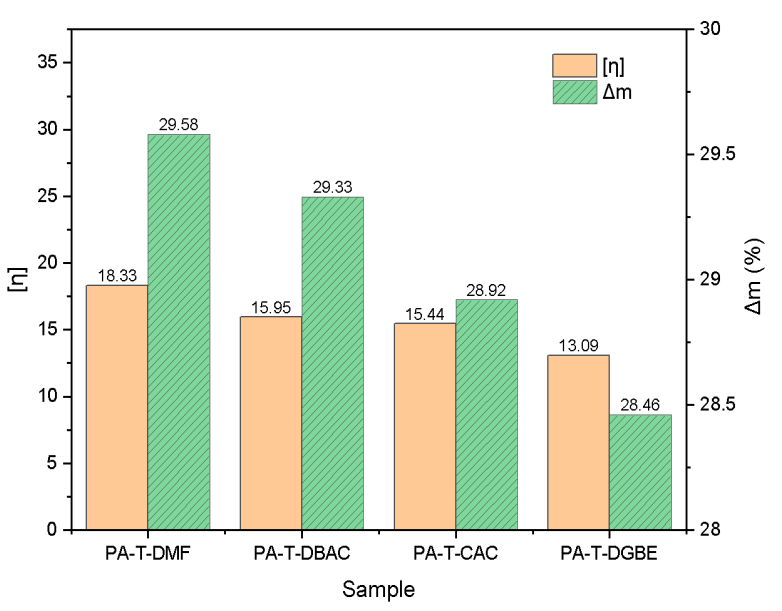

(a)

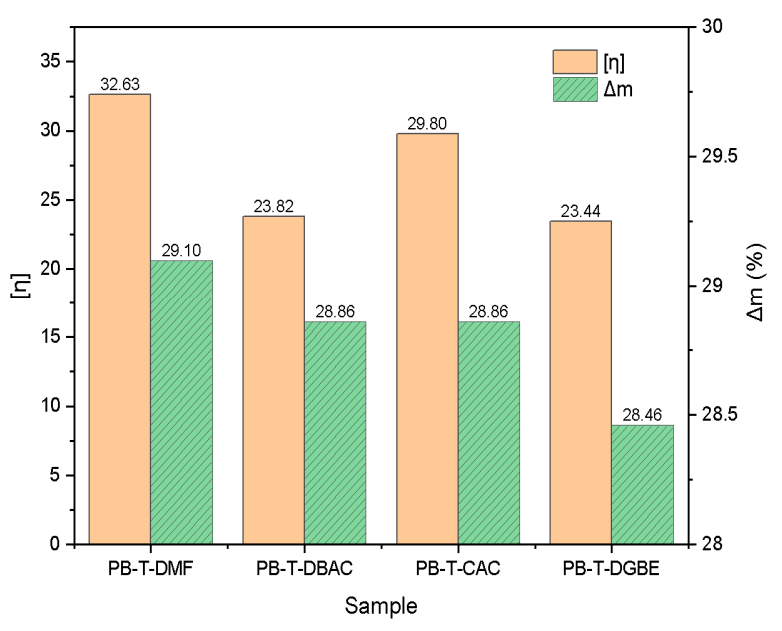

(b)

Figure 7. Intrinsic viscosity $(\eta)$ and mass changes $\Delta \mathrm{m}$ of organic vehicles with (a) resin $\mathrm{A}$ and (b) resin B.

\section{Conclusions}

This is an effective method to prepare mixed solvents with differential boiling points and proportions to realize the hierarchical volatilization of organics used in MLCC. Terpineol can volatilize slowly at low temperatures and rapidly at high temperatures, which is a commendable main component in mixed solvents.

The solubility parameters can be used as the theoretical basis for the selection of mixed solvents for electronic pastes, and the intrinsic viscosity can directly characterize the degree of dissolution of polymers in solvents. The closer the solubility parameters of the mixed solvent and polymer are, the greater the intrinsic viscosity of the organic vehicle is. Furthermore, intrinsic viscosity is a reasonable indicator for the thermal decomposition of resins. The thermal decomposition residue rate of organic vehicles decreases gradually 
with the increase in intrinsic viscosity, and the maximal thermal decomposition rate can reach $98.6 \%$. When preparing the organic vehicle for MLCC electronic slurries, a mixed solvent with similar solubility to the used polymer can be preferentially selected in order to achieve a low carbon residue of organic vehicles in the sintering process.

Supplementary Materials: The following are available online at https: / www.mdpi.com/article / 10.3390/polym14040685/s1, Figure S1: Contact angles of the mixed solvents on glass powder sheet. (a) T-DMF; (b)T-DBAC; (c) T-CAC; (d) T-DGBE; Videos S1-S4: Wetting processes of mixed solvents on glass powder sheet; Table S1: Three-dimensional solubility parameters of solvents and monomers of resins.

Author Contributions: Methodology J.L. and L.Q.; investigation, R.G.; validation, J.H.; resources, X.C.; writing-original draft preparation, R.G.; writing-review and editing, L.Q. and X.C. All authors have read and agreed to the published version of the manuscript.

Funding: This research was funded by Opening Foundation of State Key Laboratory of Advanced Materials and Electronic Components, grant number FHR-JS-201909006.

Institutional Review Board Statement: Not applicable.

Informed Consent Statement: Not applicable.

Data Availability Statement: The data presented in this study are available on request from the corresponding author.

Conflicts of Interest: The authors declare no conflict of interest.

\section{References}

1. Huang, C.R.; Tang, H.; Song, Z.F.; An, K.R. Development tendency and applications of MLCCs in 5G field. Electron. Compon. Mater. 2018, 37, 1-4.

2. Lu, G.G.; Xuan, T.P. Development tendency and research process of the electronic paste. Met. Funct. Mater. 2008, 15, 48-52.

3. Akhtar, M.; Anklekar, R.M. Characterization of copper pastes for end termination application of base metal electrode MLCCs. Microelectron. Int. 2004, 21, 36-40. [CrossRef]

4. Paik, U.; Kang, K.M.; Jung, Y.G.; Kim, J. Binder removal and microstructure with burnout conditions in BaTiO3based Ni-MLCCs. Ceram. Int. 2003, 29, 939-946. [CrossRef]

5. Wang, T.; Chen, X.; Lu, G.Q.; Lei, G.Y. Low-Temperature Sintering with Nano-Silver Paste in Die-Attached Interconnection. J. Electron. Mater. 2007, 36, 1333-1340. [CrossRef]

6. Khazaka, R.; Mendizabal, L.; Henry, D. Review on Joint Shear Strength of Nano-Silver Paste and Its Long-Term High Temperature Reliability. J. Electron. Mater. 2014, 43, 2459-2466. [CrossRef]

7. Bai, J.G.; Lei, T.G.; Calata, J.N.; Lu, G.Q. Control of nanosilver sintering attained through organic binder burnout. J. Mater. Res. 2007, 22, 3494-3500. [CrossRef]

8. Liu, X.Q.; Su, X.L.; Liu, X.F.; Qu, Y.H. Effects of sintering processing on conductivity of copper paste. J. Mater. Sci. Eng. 2015, 33, 112-116.

9. Gan, W.P.; Zhou, H.; Zhang, J.L. Investigation of sintering process and electrical conductivity of the lead-free Ag paste. Electron. Compon. Mater. 2010, 29, 65-69.

10. Ma, X.Q.; Zhu, X.Y.; Long, J.M.; Cao, M. Research status and development tendency of sintering process for electronic paste. Hot. Work. Technol. 2017, 46, 14-19.

11. Luo, S.Y.; Peng, Y.Y.; Hao, Y.P.; Chen, Q. Volatility of organic vehicle for electronic paste. Electron. Compon. Mater. 2006, 25, 49-51.

12. Fan, M.N.; Tian, X.L.; Xiong, Z.; Zhang, Y.; Xing, Q.S.; Li, J.P.; Zhao, L. Effect of solvent type on the volatility characteristics and rheological properties of silver paste. Precious. Met. 2015, 36, 104-107.

13. Fu, X.C.; Shen, W.X.; Yao, T.Y.; Hou, W.H. Physical Chemistry, 5th ed.; Higher Education Press: Beijing, China, 2005.

14. Zhang, J.Q.; Du, Y.G.; Zhang, W.J.; Yang, J.; Zheng, X.H. Study on Volatility of Organic Vehicle in Thick Film Resistance Paste. Electron. Compon. Mater. 2003, 22, 40-42.

15. Gan, W.P.; Pan, Q.Z.; Zhou, J. Effect of Organic Vehicle and Sintering Process on Conductive Properties of Silver Paste. Min. Metall. Eng. 2014, 34, 118-121.

16. Chen, X.L.; Pu, Y.P.; Wu, S.H.; Zhang, N.; Zhao, X. Influence of volatility of organic vehicle on the performances of Al electrode of PTC ceramics. Electron. Compon. Mater. 2010, 29, 22-24.

17. da Costa, F.A.; da Silva, A.G.P.; Filho, F.A.; Gomes, U.U. Influence of the composition and the tungsten particle size on the sintering of W-Cu composites. In Proceedings of the World Powder Metallurgy Congress and Exhibition, Florence, Italy, 10-14 October 2010; pp. 1884-2022.

18. Sun, W.T. Conduction Mechanism of Electronic Thick Film Material of Base Metal. Electron. Compon. Mater. 1996, 16, 14-19. 
19. Eom, Y.S.; Son, J.H.; Lee, H.S.; Choi, K.S.; Bae, H.C.; Choi, J.Y.; Moon, J.T. Development of Copper Electro-Plating Technology on a Screen-Printed Conductive Pattern with Copper Paste. J. Microelectron. Packag. Soc. 2015, 22, 51-54. [CrossRef]

20. Small, P.A. Some factors affecting the solubility of polymers. J. Appl. Chem. 1953, 3, 71-80. [CrossRef]

21. Fedors, R.F. A Method for Estimating Both the Solubility Parameters and Molar Volumes of Liquids. Polym. Eng. Sci. 1974, 14, 147-154. [CrossRef]

22. Sun, Z.J.; Zhang, X.Y.; Huang, H.; Fu, H.Q.; Chen, H.Q. Application of Solubility Parameters in the Synthesis of High solids Acrylic Resin. J. Shenyang Jianzhu Univ. Nat. Sci. 2006, 22, 592-595.

23. Yang, L.; Le, Y.L. Nonlinear mathematical model for calculating solubility parameters of mixed solvents. Paint Coat. Ind. 2001, 31, 20-21.

24. Han, K.H.; Jeon, G.S.; Hong, I.K.; Lee, S.B. Prediction of solubility parameter from intrinsic viscosity. J. Ind. Eng. Chem. 2013, 19, 1130-1136. [CrossRef]

25. Eom, Y.; Kim, B.C. Solubility parameter-based analysis of polyacrylonitrile solutions in N, N-dimethyl formamide and dimethyl sulfoxide. Polymer 2014, 55, 2570-2577. [CrossRef]

26. Flory, P.J.; Fox, T.G. Treatment of intrinsic viscosities. J. Am. Chem. Soc. 1951, 73, 1904-1908. [CrossRef]

27. Alfrey, T.; Bartovics, A.; Mark, H. The effect of temperature and solvent type on the intrinsic viscosity of high polymer solutions. J. Am. Chem. Soc. 1942, 64, 1557-1560. [CrossRef]

28. Hansen, C.M. Applications - Coatings and other filled polymer systems. In Hansen Solubility Parameters: A User's Handbook; CRC Press: Boca Raton, FL, USA, 2000; pp. 137-149.

29. Ye, L.N.; Liu, M.F.; Huang, Y.W.; Zhang, Z.W.; Yang, J.X. Effects of Molecular Weight on Thermal Degradation of Poly $(\alpha-$ methyl styrene) in Nitrogen. J. Macromol. Sci. Part B Phys. 2015, 54, 1479-1494. [CrossRef]

30. Reich, L.; Stivala, S.S. Elements of Polymer Degradation; McGraw-Hill: New York, NY, USA, 1971; p. 186

31. Vollhardt, K.P.C.; Schore, N.E. Organic Chemistry, 2nd ed.; Freeman: New York, NY, USA, 1994; p. 111.

32. Chen, Z.B.; Yang, S.S.; Meng, T. Study on Thermal Life of Acrylic Resin for Fireproof Coatings. J. Armed Police Acad. 2018, 34, $14-16$.

33. Czech, Z.; Pełech, R. Thermal degradation of butyl acrylate-methyl acrylate-acrylic acid-copolymers. J. Therm. Anal. Calorim. 2009, 96, 583-586. [CrossRef]

34. Czech, Z.; Pełech, R. The thermal degradation of acrylic pressure-sensitive adhesives based on butyl acrylate and acrylic acid. Prog. Org. Coat. 2009, 65, 84-87. [CrossRef]

35. Yang, X.F.; Xie, H.H.; He, Q.L.; Zhou, Z.; Xu, X.W.; Zhang, L.; Xie, Z.P. Study of thermal degradation mechanism of binders for ceramic injection molding by TGA-FTIR. Ceram. Int. 2019, 45, 10707-10717.

36. Czech, Z.; Agnieszka, K.; Ragańska, P.; Antosik, A. Thermal stability and degradation of selected poly (alkyl methacrylates) used in the polymer industry. J. Therm. Anal. Calorim. 2015, 119, 1157-1161. [CrossRef] 